\title{
Auditory Sensitivity of an Acoustic Parasitoid (Emblemasoma sp., Sarcophagidae, Diptera) and the Calling Behavior of Potential Hosts
}

\author{
H.E. Farris ${ }^{a-c}$ M.L. Oshinsky ${ }^{b}$ d T.G. Forrest ${ }^{a, e}$ R.R. Hoy ${ }^{b}$ \\ ${ }^{a}$ National Center for Physical Acoustics, University of Mississippi, Oxford, Miss., b Section Neurobiology and \\ Behavior, Cornell University, Ithaca, N.Y., 'Center for Neuroscience, LSU Health Science Center, New Orleans, La., \\ ${ }^{\mathrm{d}}$ Department of Neurology, Thomas Jefferson University, Philadelphia, Pa., e Department of Biology, University of \\ North Carolina-Asheville, Asheville, N.C., USA
}

\section{Key Words}

Cicada $\cdot$ Diel behavior $\cdot$ Parasitoid $\cdot$ Cricket $\cdot$ Chorus $\cdot$

Tibicen · Ormia $\cdot$ Emblemasoma $\cdot$ Phonotaxis · Interneuron • Frequency tuning

\begin{abstract}
Using field broadcasts of model male calling songs, we tested whether Tibicen pruinosa and T. chloromera (Hemiptera: Cicadidae) are candidate hosts for acoustic parasitoid flies. The model calling song of T. pruinosa attracted $90 \%$ of the flies (Sarcophagidae: Emblemasoma sp.; all larvapositing females) when broadcast simultaneously with the model T. chloromera song, a phonotactic bias reconfirmed in single song playbacks. In paired broadcasts of model T. pruinosa songs with different relative amplitudes ( $3 \mathrm{~dB}$ or $6 \mathrm{~dB}$ ), significantly more flies were attracted to the more powerful song, a result consistent with the responses predicted by a model proposed by Forrest and Raspet [1994]. Using intracellular recordings and dye injections, we characterized the sensitivity of auditory units in sound-trapped flies. Intracellular recordings from six auditory units (5 interneurons, 1 afferent) revealed best sensitivity for frequencies near 3-4 $\mathrm{kHz}$, matching the predominant spectral components of the calling songs of both species of cicada. Interestingly, although flies could be attracted to T. pruinosa broadcasts throughout the day, hourly censuses of singing males revealed that calling occurred exclusively at dusk. Further-
\end{abstract}

\begin{tabular}{ll}
\hline KARGER & ๑ 2008 S. Karger AG, Basel \\
Fax +41613061234 & \\
$\begin{array}{l}\text { E-Mail karger@karger.ch } \\
\text { www.karger.com }\end{array}$ & $\begin{array}{l}\text { Accessible online at: } \\
\text { www.karger.com/bbe }\end{array}$
\end{tabular}

more, the duration of the dusk chorus in T. pruinosa was significantly shorter than the midday chorus of the less attractive song of $T$. chloromera. We propose that the tight temporal aggregation of the dusk chorus time could function to reduce risk from attracted parasitoids.

Copyright $\odot 2008$ S. Karger AG, Basel

\section{Introduction}

In some species of acoustically signaling insects male calling songs not only attract conspecifics, but also acoustically orienting parasitoids [Cade, 1975; Soper et al., 1976; Lehmann, 2003]. For example, several species of ormiine flies (Tachinidae) are acoustic parasitoids of a variety of singing orthopterans [Burk, 1982; Lakes-Harlan and Heller, 1992; Allen, 1995]. Although the larvae of ormiines will successfully develop in several potential host species [Wineriter and Walker, 1990; Walker and Wineriter, 1991; Shapiro, 1995], host-searching female flies exhibit acoustic selectivity that is based on the spectral and temporal parameters of the hosts' songs [Fowler, 1987; Walker, 1993]. With respect to song frequency, the interspecific variance in host songs for ormiines is large, ranging over 4 octaves [2.7- $40 \mathrm{kHz}$; Fowler, 1987; Stumpner and Lakes-Harlan, 1996; Lehmann and Heller, 1998; Stumpner et al., 2007]. So far, sensitivity in ormiine flies is shown to track this variation with tuning match-

\footnotetext{
H.E. Farris

Center for Neuroscience, LSU Health Science Center

2020 Gravier St.

New Orleans, LA 70112 (USA)

Tel. +1 504599 0865, Fax +1 504599 0891, E-Mail hfarri@lsuhsc.edu
} 
ing the spectral range of hosts' songs in one of two general patterns: relatively sharper tuning to a host frequency range (O. ochracea, 4-8 kHz) [Robert et al., 1992; Oshinsky and Hoy, 2002] or broader tuning that encompasses a range of host songs with very different spectra, facilitating host switching (e.g., Therobia leonidei and Homotrixa alleni) [Stumpner and Lakes-Harlan, 1996; Stumpner et al., 2007].

Acoustic parasitism in Diptera is not limited to the orthopteran-tachinid system, however. Members of the family Sarcophagidae (Emblemasomatini) use an independently evolved ear [Edgecomb et al., 1995; Robert et al., 1999; Lakes-Harland et al., 1999] to carry out an analogous strategy for finding their hosts, singing cicadas [Soper et al., 1976]. Like that for ormiines, there appears to be interspecific variance in host choice, as several species of flies, found either as larvae or reared to adults, have been collected from various parasitized cicada taxa [Lopes, 1971, 1981; Soper et al., 1976]. All Emblemasoma examined so far express the inflated prosternum known to be the tympanal organ [Lopes, 1971; Lakes-Harlan et al., 1999; Robert et al., 1999], suggesting that host choice is based on auditory cues. At present, although there are limited data regarding the auditory mechanisms, behavior and sensitivity of sarcophagids, two interesting differences with ormiines have emerged. First, the mechanical modes of vibration of the tympanal organ differ from those in ormiines [Robert et al., 1999]. Second, sensitivity in Emblemasoma auditrix [genus formerly Colcondamyia; Pape, 1990] differs from the two patterns in ormiines, as whole nerve recordings from interneurons in the neck connectives show evidence for a tuning mismatch: best responses occur at $5 \mathrm{kHz}$, almost an octave below the dominant frequency of its host's song $(9 \mathrm{kHz})$, suggesting discrimination among the songs of different cicada species is not based on spectral cues [Köhler and Lakes-Harlan, 2001]. In addition to the tuning mismatch, E. auditrix also exhibits a sharp decrease in physiological sensitivity to low frequencies $(<5 \mathrm{kHz})$ [Lakes-Harlan et al., 1999; Köhler and Lakes-Harlan, 2001]. Having data on the sensitivity of only one sarcophagid species, of course, does not answer the question regarding the extent of convergence with ormiines; that is, whether the mechanisms and patterns of sensitivity consistently differ between the analogous traits. To explore this question, we investigated the sensitivity and behavior of parasitoids of cicadas that produce low frequency calls.

Using field broadcasts of calling songs, our study shows that the relatively low frequency $(3.5 \mathrm{kHz})$ call of Tibicen pruinosa (Cicadae) is attractive to acoustic para- sitoid flies (Emblemasoma sp.). Because most of the spectral energy in the $T$. pruinosa call is below the tuning previously shown for E. auditrix, specialization for sensitivity to this low frequency song was measured in the auditory units of attracted flies using intracellular recordings and dye injections. In addition, we show that T. pruinosa exhibits a tightly timed and short duration chorus, making simultaneous comparisons important to phonotactic host choice. Thus, we used paired broadcasts of the T. pruinosa song that varied in relative intensity and spatial separation to assess the behavioral threshold and phonotactic decision rules employed in the field by hostsearching flies [Forrest and Raspet, 1994].

\section{Methods}

\section{Census of Cicada Community}

To assess the potential hosts for sarcophagid flies near our field site, we made hourly censuses of calling male cicadas from 08.00 to $20.00 \mathrm{~h}$ (Central Daylight Time) during ten days between 24 July and 24 August 1992 on the University of Mississippi campus, Lafayette County, Mississippi. Average sunrise and sunset times during the census were $05.42( \pm 15)$ and $19.56( \pm 21) \mathrm{h}$, respectively. For each census at least one person walked a seven station circular route through an area of large mixed hardwood trees (distance from station to station was ca. $90 \mathrm{~m}$ ). At the beginning and end of each census, temperatures were measured in direct sunlight and in the shade using a Fluke 8062 multimeter and a Fluke 80T-150U temperature probe. Mean ambient temperature for each hourly observation was calculated by averaging these four temperature measures. At each of the seven stations, relative light intensity was measured on a 12 unit logarithmic scale with a General Electric light meter. One minute was spent at each station counting the number of individual cicadas calling within earshot. A complete circuit of the census took approximately 20 min.

During the census, visual observation of individual cicadas was impossible because they called high in the treetops. There were three species, however, Tibicen pruinosa, T. chloromera and Neocicada hieroglyphica, that were easily distinguished by differences in their calling songs, allowing individual calling males to be singled out and censused by ear. Although the songs of T. pruinosa and T. chloromera cover similar bandwidths, their temporal structure is very different (see fig. 1a, b). T. pruinosa produces an FM burst at a relatively slow rate (1.4-1.6 burst/s), and T. chloromera produces a noisy broadband burst without FM at a faster rate (10-13 bursts/s). The song of Neocicada hieroglyphica is easily distinguished from the other two as it exhibits both a higher frequency band and faster temporal structure (peak freq.: $4.8 \pm$ $0.12 \mathrm{kHz}$; harmonic: $9.11 \pm 0.25 \mathrm{kHz} ; 200$ minimum - 375 maximum pulses/s. Parameters for N. hieroglyphica are from 2 randomly selected 12 second sections from 1 song each from 3 individuals recorded at the field site).

Because some males might have flown to different perches as we walked the census circuit, individuals may have been counted more than once in an hourly census. Therefore, we normalized 
the hourly census for each day as a proportion of the maximum hourly count for that day. Thus, each day's maximum hourly census was 1.0 and all other hourly counts ranged between 0 and 1.0. This technique does not give an accurate measure of the number of calling cicadas but does reflect relative calling diversity and activity per hour.

We determined the autocorrelation function of the census data to test for significant periodicity in the series of hourly observations [Chatfield, 1989]. Certain assumptions were made in using this method of analysis. Because there was no evidence of cicada singing during the nighttime hours between 21.00 and 07.00, the census was not taken during this time. For these hours, cicada broadcast activity was designated a census level of 0 . The relationships between temperature and sunlight intensity and cicada calling activity were analyzed using logistic regression [Hosmer and Lemeshow, 1989]. This method of analysis allows for the input of a binomial dependent variable (e.g., weighted number of calling males) and compares the data to a $\chi^{2}$ distribution with 1 degree of freedom. A two-tailed t test was used to compare the mean temperatures for the times with the maximum amount of male calling in both species. Comparison of the distribution of calling times between T. chloromera and T. pruinosa was calculated using a variance ratio test [Zar, 1984].

\section{Sound Synthesis for Field Broadcasts}

All acoustic stimuli were generated using a personal computer and custom written software. The digital stimuli were played back using a Tucker-Davis Technologies (TDT) 16-bit digital-toanalog converter (sample period $40 \mu \mathrm{s}$ ) with the output low-pass filtered at $10 \mathrm{kHz}$ using a TDT filter (75 $\mathrm{dB}$ /octave) to prevent aliasing.

The model T. pruinosa and N. hieroglyphica broadcasts consisted of the continuous playback of a digitally sampled portion of an exemplar call (fig. 1). The sampled portion was the most prominent repeated element in the middle of the calls [Alexander, 1960]. The exemplar was taken from recordings of singing males near our broadcast site $(<6.4 \mathrm{~km})$ using an E.P.M. model p650 parabolic microphone, a Sony TCD5 Pro2 analog cassette recorder and a TDK SA-X tape. The spectrum of the calling song was analyzed using the complex FFT routine in Mathcad (Cambridge, Mass., USA). Any effects of temperature on song structure were not included, as it was impossible to measure the ambient temperature at the positions of the calling males [note that ambient temperature may or may not affect the carrier frequency of the calling song; Josephson and Young, 1979].

Unlike the T. pruinosa song, which contains varying intensity across frequency bands and frequency modulation, the T. chloromera song consists of the repetition of a broadband burst. Thus, the $T$. chloromera model song was constructed by digitally synthesizing a song pulse (fig. 1) with the $40 \mathrm{~dB}$ bandwidth and temporal properties of those recorded from a singing male.

There are experimental limitations in using the model calls. First, the models represent only a portion of an actual male calling song and do not include 'wind-up' or 'wind-down' segments. Although these segments could be relevant to flies, their variance (particularly in duration and intensity) would have created times during playback in which song intensity differed [a parameter important to phonotaxis, see below; Wyttenbach and Farris, 2005]. Second, the models also eliminate between-male variance, which could also affect fly attraction; the models thus are valid

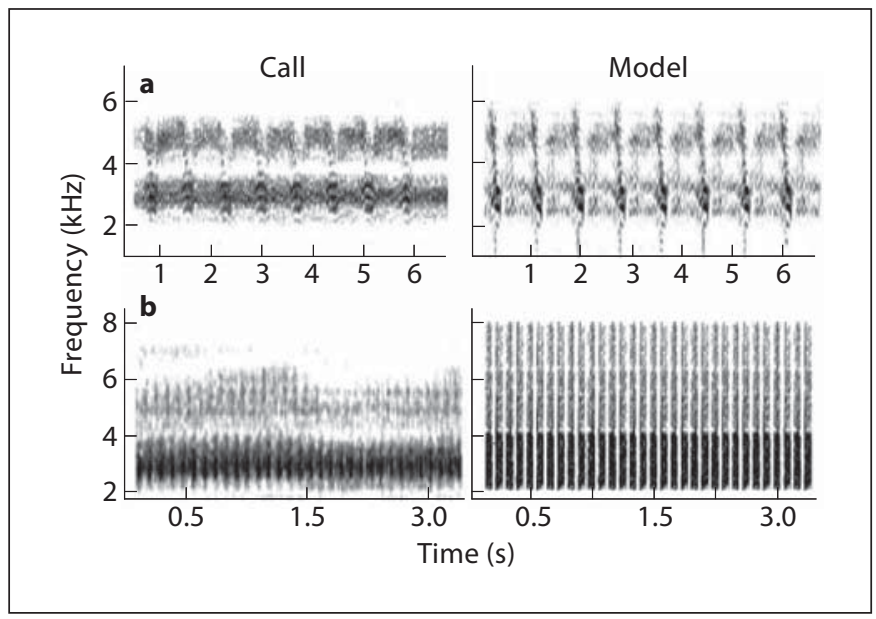

Fig. 1. Spectrograms of recorded and model calling songs of T. pruinosa (a) and T. chloromera (b).

for testing the effects of single variables such as intensity, as broadcasts of actual male calls would vary across several acoustic parameters. Third, when broadcasting a single model or actual call, the results might not generalize to all songs.

The model calling songs were broadcast through Motorola piezoelectric speakers. All digital song buffers had the same rms amplitude. By broadcasting a $3.5 \mathrm{kHz}$ tone, sound pressure levels $(\mathrm{SPL}$ re. $20 \mu \mathrm{Pa})$ were calibrated $10 \mathrm{~cm}$ above each speaker $( \pm 1.0$ $\mathrm{dB}$ ) before each broadcast using a custom built microphone holder rigidly mounted to the face of the speaker. After calibration to the tone, the output was switched to the song buffers and the calibration verified. SPL was measured using a Fluke 8060A multimeter (calculating root-mean-square amplitude; integration time: $100 \mathrm{~ms}$ ), a Bruel \& Kjær (B\&K) 4135 1/4 inch microphone (grid on), a B\&K 2639 preamp and a B\&K 2804 microphone power supply. The calibration system was checked using a $B \& K 4230$ pistonphone calibrator.

\section{Sound Trapping Flies}

Sound traps, consisting of a speaker mounted inside a 19-liter mesh bucket, were placed in an area of mixed hardwoods at the University of Mississippi Biological Field Station, Lafayette, Co., Miss., USA. Similar to the slit traps designed for trapping O. ochracea [Walker, 1989], a $12 \times 3 \mathrm{~cm}$ tapered slit in the lid of the bucket trap allowed flies (Emblemasoma sp.: Sarcophagidae) to enter but not to escape. Broadcasts were carried out during September 10-20, 1996-1998. During this time, males of all three cicada species were heard calling near the broadcast site.

Preliminary data showed no fly attraction to the model N. hieroglyphica song (see below). Thus, field experiments focused on the response of flies to broadcasts of the T. pruinosa or T. chloromera model songs. First, to assess relative attractiveness, model calling songs were broadcast from either of two separate traps (109 dB, $5 \mathrm{~m}$ trap separation). The effects of the intensity of the calling songs and the distance between sources on the attraction of parasitoid flies were subsequently tested by broadcasting the model $T$. pruinosa song from both traps at two different relative 
intensities ( $\Delta 6$ and $\Delta 3 \mathrm{~dB}, 5 \mathrm{~m}$ separation) and separations (5 and $10 \mathrm{~m}$ separation, $\Delta 6 \mathrm{~dB}$ ). Broadcast conditions were: 109 vs. 103 $\mathrm{dB}$ and 109 vs. $106 \mathrm{~dB}, 5 \mathrm{~m}$ separation and 109 vs. $103 \mathrm{~dB}, 10 \mathrm{~m}$ separation. The sound traps were checked every $30 \mathrm{~min}$ and the flies in each trap were collected. Note that as shown previously, flies often sat on the outside of the trap for several minutes [Schniederkötter and Lakes-Harlan, 2004; cf. O. ochracea, Walker, 1993]. Although some flies subsequently entered the trap, those that did not were captured by hand in vials and included in the data. There was no recognizable anatomical difference between those captured outright and those by hand.

Broadcasts began in the morning prior to the mid-day chorus of $T$. chloromera (see below) and continued until after sunset. To avoid the effect of trap position on relative attraction, the two songs in each broadcast condition were alternated between the two trap positions until approximately the same number of flies was attracted in both configurations. A Tukey-type test for multiple comparisons between proportions compared the relative responses to field broadcasts [proportion of the total attracted flies at each trap; Zar, 1984]. A chi-square goodness-of-fit test was used to test whether the relative response proportions differed from random or model predictions.

\section{Physiological Recordings}

Cold-anesthetized female flies (Emblemasoma sp; soundtrapped with $T$. pruinosa song) were mounted on a platform dorsal side up in a foam lined Faraday cage that reduced acoustic and electrical noise. Using a dorsal dissection so as not to interfere with the ventrally located hearing organ [Lakes-Harlan et al., 1999; Robert et al., 1999], the fly's flight muscles and gut were removed to reveal the fused thoracic ganglion. Electrical activity in auditory units in the fused ganglion was recorded using thinwalled $(1.0 \mathrm{~mm}$ o.d.) borosilicate glass, micropipette electrodes filled at the tip with 2.5\% Lucifer Yellow (Sigma) and backfilled with $0.1 \mathrm{~mol}^{-1} \mathrm{LiCl}$. Electrode resistance varied from 70 to 140 $\mathrm{M} \Omega$. The indifferent electrode was inserted into the thorax. The search stimulus used to locate auditory units consisted of a $10 \mathrm{~ms}$ tone pulse (1 ms ramps) of 5-7 kHz. After amplification (AM systems model 1600 DC amplifier), the neural responses were digitized (10 $\mu$ s sampling period) using a TDT AD3 and System II Array Processor and custom written software. By injecting hyperpolarizing current (0.2-1.2 nA) after recording, cells were stained with Lucifer Yellow for anatomical identification. After staining, the ganglia were dissected and fixed (16-24 h) in $4 \%$ paraformaldehyde ( $\mathrm{pH}$ 7.4), dehydrated in an ascending ethanol series and cleared using methyl salicylate. Stained cells were photographed and digitized as whole mounts using a Leitz Dialux 20 and BioRad MRC-600 confocal microscopes, respectively. Cell identification (i.e., interneuron or afferent) was accomplished by comparing micrographs of the Lucifer fills to those produced by backfilling the chordotonal auditory organ with Neurobiotin/ ABC kit (vector labs) or fluorescent dextrans (Molecular Probes Inc. Texas Red D-3328 or FITC D-3306), a procedure which only illuminates afferents. Although all cells were partially filled, this distinction could still be made.

After penetrating a cell, its frequency tuning was determined by measuring the minimum sound pressure level $( \pm 3 \mathrm{~dB})$ required to elicit at least 1 action potential in $3 / 5$ stimulus presentations. Stimuli were pure tones that varied in frequency from 2 to $35 \mathrm{kHz}$ (20 ms pulses, $1 \mathrm{~ms}$ ramps, $100 \mathrm{~ms}$ ISI) and were present-

Auditory Sensitivity in Sarcophagid Flies
Table 1. Correlations between environmental variables and proportion of males singing

\begin{tabular}{lcrr}
\hline Species & Parameter estimate & $\chi^{2}$ value & \multicolumn{1}{c}{$\mathrm{p}$} \\
\hline T. chloromera & (mid-day chorus) & & \\
Light & 0.0196 & 0.34 & 0.5586 \\
$\Delta$ Light & 0.6606 & 138.00 & $<0.0001$ \\
Temp & -0.0110 & 0.18 & 0.6741 \\
$\Delta$ Temp & 0.2111 & 20.19 & $<0.0001$ \\
T. pruinosa & (dusk chorus) & & \\
Light & -1.3307 & 121.04 & $<0.0001$ \\
$\Delta$ Light & 0.5360 & 15.22 & $<0.0001$ \\
Temp & 0.0534 & 0.69 & 0.4060 \\
$\Delta$ Temp & 0.0858 & 0.95 & 0.3302 \\
\hline
\end{tabular}

Columns are: species and environmental variable, logistic regression parameter estimate (slope), chi-square value and the $\mathrm{p}$ value relative to a chi-square distribution with 1 d.f.

ed in ascending order. During measurement of the tuning curve, input/output (I/O) functions at each cell's characteristic frequency were measured by calculating the mean number of spikes elicited for the five repetitions presented at each intensity step. Tuning curves showed linear change in sensitivity around the best frequency (see results) and thus were analyzed using a simple linear regression.

\section{Results}

\section{Census of Available Cicada Hosts}

The census was necessary to catalog which potential hosts were present and when they were at risk of attracting larvapositing flies. In the area of our field site we identified 3 species of singing cicadas, $N$. hieroglyphica, $T$. chloromera and T. pruinosa. Although N. hieroglyphica called throughout the day, T. pruinosa and T. chloromera called at distinct times. For T. chloromera, $87 \%(\mathrm{n}=360$ individuals) of singing was observed between 08.00 and $11.00 \mathrm{~h}$ (mean temperature: $\left.23 \pm 3^{\circ} \mathrm{C}\right)$, whereas $92 \%(\mathrm{n}=$ 105) of singing by $T$. pruinosa occurred between 19.00 and $20.00 \mathrm{~h}$ (mean temperature: $23^{\circ} \mathrm{C} \pm 3$ ) (fig. 2). Mean temperature for these two times did not differ significantly ( $\mathrm{p}=0.5, \mathrm{t}=2.0, \mathrm{n}=50)$. Chorus duration for T. chloromera is significantly broader than that in T. pruinosa (variance ratio test; $\mathrm{p}<0.001$ ). For both species, autocorrelation analysis of male signaling times revealed consistent $24 \mathrm{~h}$ periodicities, as the highest correlations between observations of singing males were $24 \mathrm{~h}$ apart (fig. 3). Thus, the broader duration chorus time of T. chlo- 


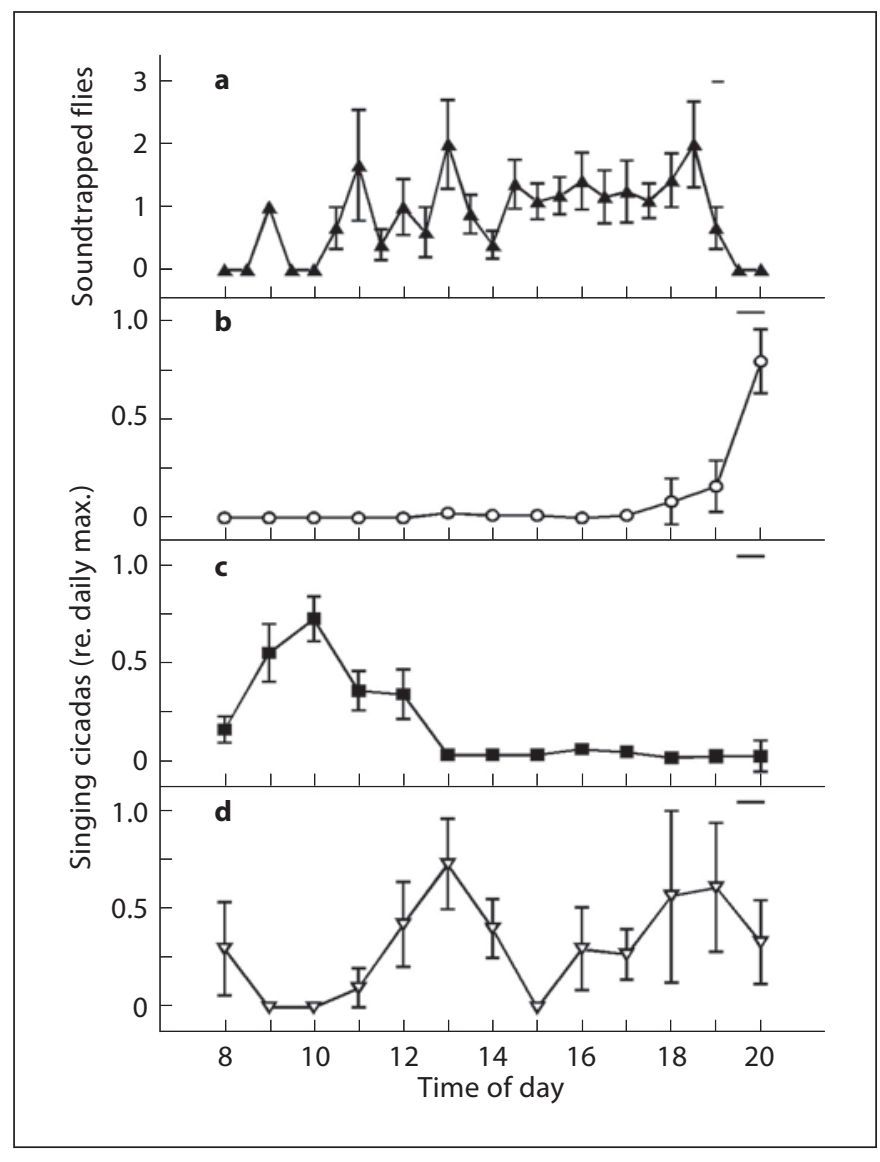

Fig. 2. a Mean ( \pm SD) number of flies trapped at the continuous broadcast of a model $T$. pruinosa calling song at half-hour intervals on two different days ( $\mathrm{n}=44$ flies). $\mathbf{b}$-d Arithmetic mean proportion $( \pm \mathrm{SD})$ of singing cicadas, T. pruinosa (a); T. chloromera $(\mathbf{c}) ; N$. hieroglyphica $(\mathbf{d})$ relative to the time of day. No census was taken from 21.00 to $07.00 \mathrm{~h}$. Solid horizontal lines represent the range of sunset times for the data.

romera cannot be the result of a shift in chorus time across the days of our census.

The calling activity of both species was significantly correlated to changes in light intensity between censuses (table 1). In T. chloromera, the species with the pre-noon chorus, singing was also correlated to changes in ambient temperature. However, for T. pruinosa the species which choruses primarily at dusk, calling activity was not influenced by temperature, but was significantly correlated with the levels of ambient light (table 1).

\section{Attraction of Flies}

Two of the model cicada songs attracted larvapositing female sarcophagid flies [Emblemasoma sp.; genus de-

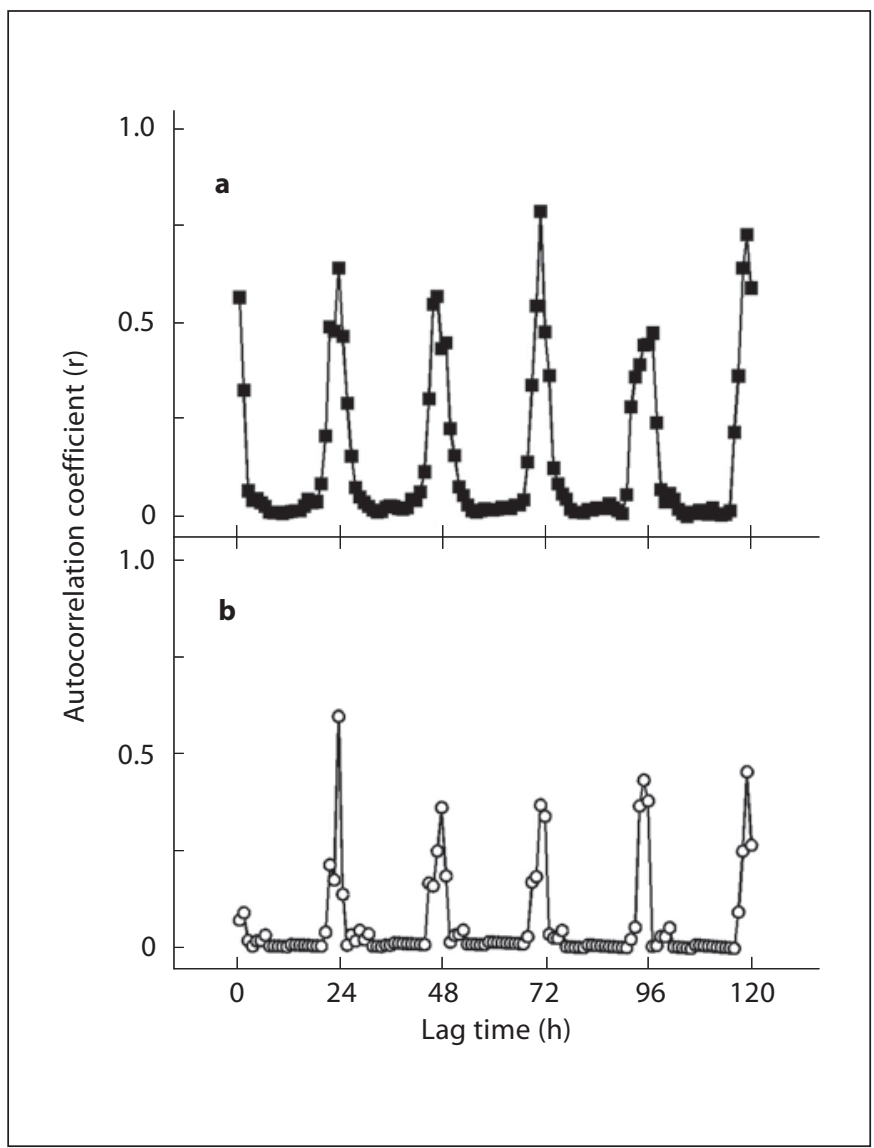

Fig. 3. Correlograms of the time series data for diel calling in T. chloromera (a) and T. pruinosa (b). Each point represents the autocorrelation coefficient for each 1 hour lag of the first $120 \mathrm{~h}$ of the observations (lags begin at $1 \mathrm{~h}$ ). The ten days of census were combined to form a continuous time series. To complete the $24 \mathrm{~h}$ of observations, census levels of 0 were given to the hours of 21.00 to 07.00 , when no cicadas called. Autocorrelation coefficient (r) values are greatest at a period of $24 \mathrm{~h}$ for both species.

termined from Aldrich, 1916]. Unfortunately, attraction of only females prevented their specific identification, as the taxonomy of this group is based in part on male genitalia [Pape, 1990; personal communication]. Single speaker broadcasts over $32 \mathrm{~h}$ of the $N$. hieroglyphica call failed to attract any flies (data not shown). However, in $31 \mathrm{~h}$ of simultaneous broadcast (over 6 days) of the model T. pruinosa and T. chloromera calling songs, $90.3 \%$ of the flies were attracted to the T. pruinosa trap $(\mathrm{n}=82$, $\chi^{2}=29.8, \mathrm{p}<0.0001$ ). This preference for the T. pruinosa call did not appear to be due to a relative difference in attractiveness, as broadcast of the T. chloromera song alone from both traps for $3.5 \mathrm{~h}$ on one day failed to attract any flies, even though flies were present; switching 


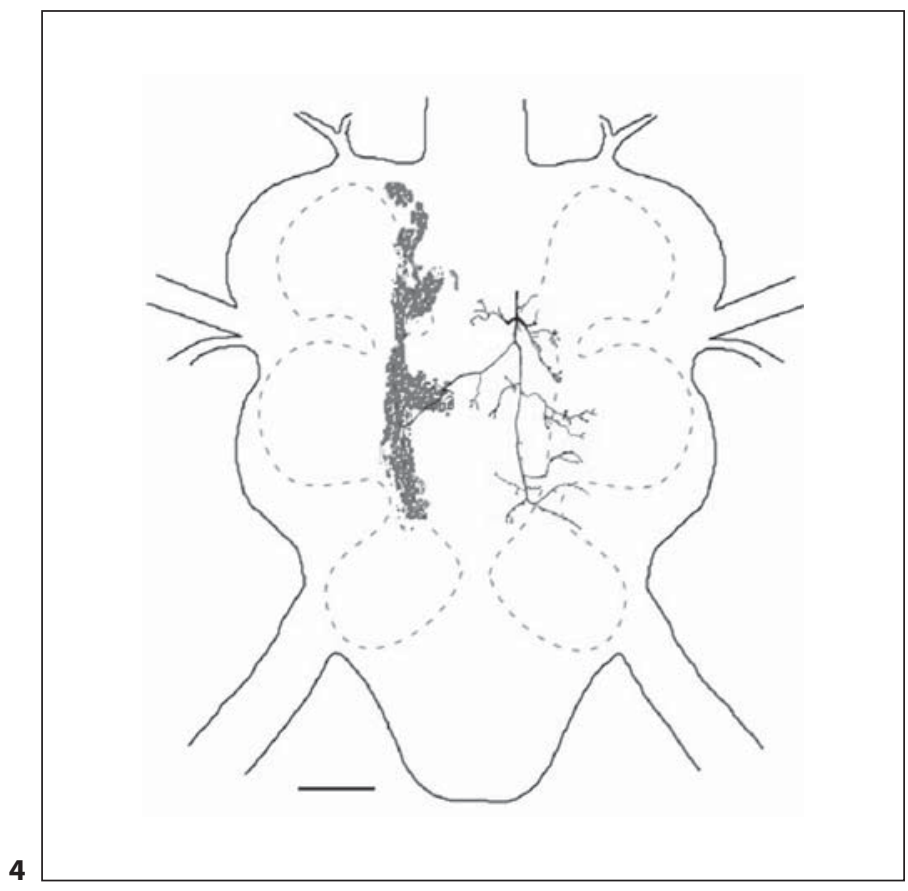

Fig. 4. Anatomy of an auditory interneuron Emblemasoma sp. (ventral view; top is anterior). Grey shaded fill is a trace from the backfill of the auditory nerve. Interneurons were identified by any contralateral projections. Scale bar is $100 \mu \mathrm{m}$.

Fig. 5. Auditory tuning curves for Emblemasoma sp. a Mean stimulus amplitude $( \pm$ SE) required to elicit a response (one action potential) in $3 / 5$ presentations. Open and closed symbols are data from interneurons $(n=5)$ and afferents $(n=1)$, respectively. Thresholds for interneurons above $10 \mathrm{kHz}$ are responses from only one cell. b Power spectrum of the T. pruinosa call.

one of the traps to the T. pruinosa song attracted two flies within one hour. Because of this attraction to the T. pruinosa song, field broadcasts were subsequently limited to experiments using the T. pruinosa song only. Continuous broadcast of this song revealed that, in contrast to diel calling patterns shown above, fly phonotaxis occurred throughout the day. On days with continuous uninterrupted broadcasts of the model $T$. pruinosa song, flies were captured from $09.00 \mathrm{~h}$ until just prior to sunset (fig. 2).

\section{Effects of Song Intensity and Spacing}

The relative attractiveness of two traps broadcasting the model $T$. pruinosa song depended on their relative intensity. For intensity differences of $3 \mathrm{~dB}$ and $6 \mathrm{~dB}$, the more intense song attracted $75-80 \%$ of the flies (table 2), although increasing the intensity difference from 3 to 6

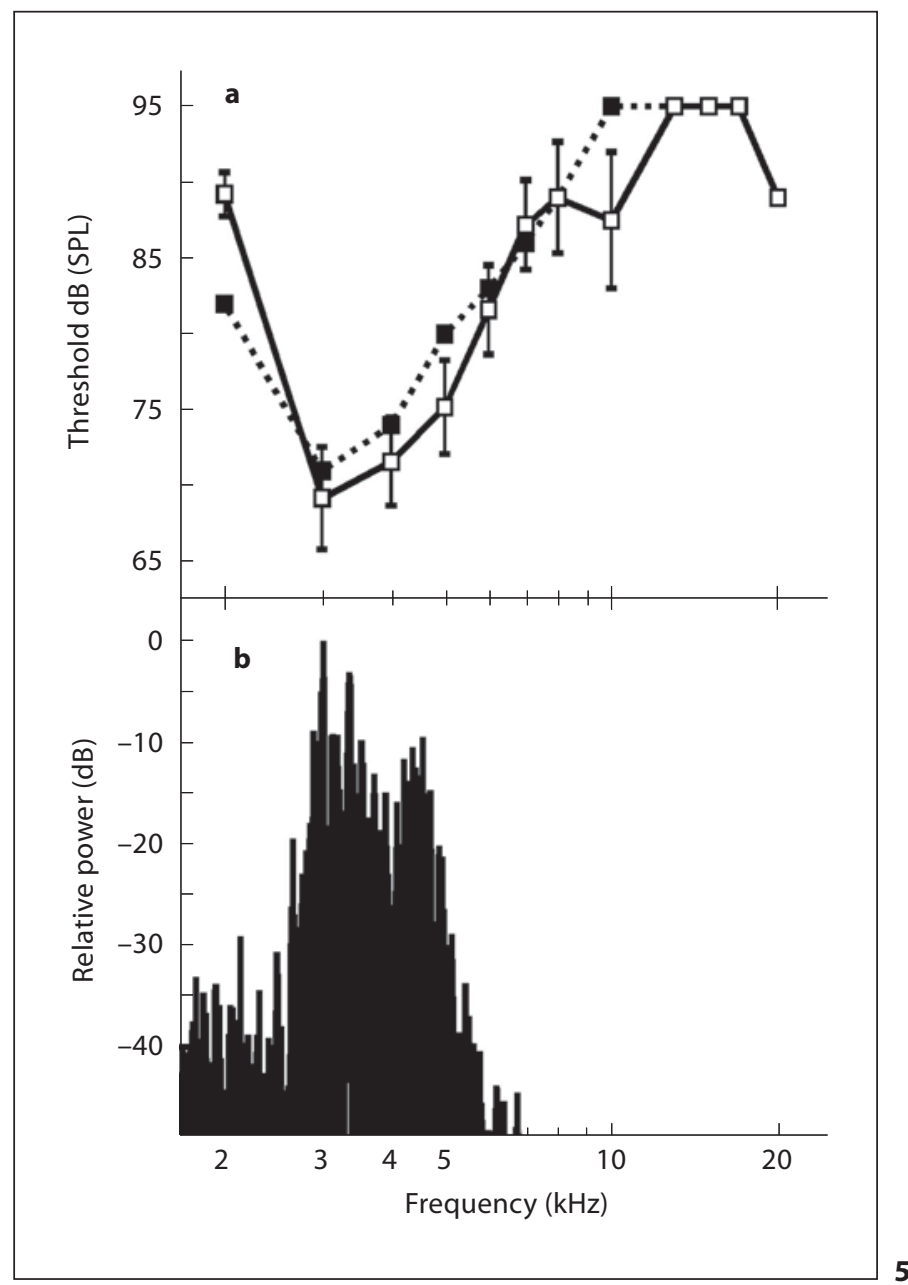

$\mathrm{dB}$ did not change the relative attractiveness of the more intense song $(q=0.804, p>0.5)$. There was no effect of trap separation on the relative attraction of flies to the two songs. For songs that differ by $6 \mathrm{~dB}$, the less intense song attracted 24.1 and $21.2 \%$ of the flies for the $10 \mathrm{~m}$ and $5 \mathrm{~m}$ separations, respectively $(\mathrm{q}=0.777, \mathrm{p}>0.5)$.

\section{Auditory Sensitivity in Emblemasoma sp.}

In contrast to interneurons recorded in the neck connectives of E. auditrix [Lakes-Harlan et al., 1999], there was no evidence of a tuning mismatch in flies attracted to the T. pruinosa song. Recordings from 5 interneurons, which exhibited intersegmental projections, and one afferent ( 1 cell each from 6 individuals) revealed consistent tuning to frequencies close to $3 \mathrm{kHz}$, the dominant frequencies of the cicadas' calling songs (fig. 4, 5). For the interneurons, tuning was sharp due to the steep reduc- 
Table 2. Relative attraction of flies to model T. pruinosa calling songs

\begin{tabular}{lllllll}
\hline $\begin{array}{l}\text { Sepa- } \\
\text { ration } \\
\text { (meters) }\end{array}$ & $\begin{array}{l}\text { CS dB SPL } \\
\text { at } 0.10 \mathrm{~m} \\
\text { S.1 vs. S.2 }\end{array}$ & $\Delta \mathrm{dB}$ & $\mathrm{N}$ & $\begin{array}{l}\mathrm{P} \\
\text { (S. 2) }\end{array}$ & $\begin{array}{l}\text { Response com- } \\
\text { parison to ran- } \\
\text { dom, } \chi^{2} \text { value }\end{array}$ \\
\hline 5 & 109 vs. 103 & 6 & 33 & 0.212 & 10.939 & $<0.001$ \\
5 & 109 vs. 106 & 3 & 33 & 0.242 & 8.758 & $<0.005$ \\
10 & 109 vs. 103 & 6 & 29 & 0.241 & 7.759 & $<0.01$ \\
\hline
\end{tabular}

Columns are: calling song separation, calling song (CS) levels for the two songs (S.1 vs. S.2), relative intensity difference between the two songs $(\Delta \mathrm{dB})$, sample size of attracted individuals $(\mathrm{N})$, proportion attracted to the quieter song $(\mathrm{P}(\mathrm{S} .2))$ and comparison of the response proportions to a random response using a chi-square goodness of fit test (1 d.f.).

tion in sensitivity from $3 \mathrm{kHz}$ to $2 \mathrm{kHz}(20 \pm 5 \mathrm{~dB})$. The reduced sensitivity for frequencies above $3 \mathrm{kHz}$ was also steep (linear slope: $3.1 \pm 0.6 \mathrm{~dB} / \mathrm{kHz}$ up to $10 \mathrm{kHz} ; \mathrm{r}^{2}=$ $0.92, \mathrm{p}<0.004)$, with little sensitivity above $6 \mathrm{kHz}$ and only one recording showing minimal sensitivity above 10 $\mathrm{kHz}$. This sensitivity is similar to that of the afferent, but the single sample prevents statistical comparison or general description of receptor tuning. Thus, based on the center frequency and tuning sharpness of these auditory units, spectral sensitivity in these flies appears to match that of the most attractive song.

Although sound trapping data show that these flies could be making phonotactic choices based on relative intensity [table 2; but see Forrest and Raspet, 1994], the response to single pulses of $3 \mathrm{kHz}$ suggests that the interneurons recorded here do not contribute to intensity coding as both the latency and I/O functions varied little with pulse intensity (the single afferent offers anecdotal evidence of such coding, however; fig. 6).

\section{Discussion}

Stemming from the difficulty in both capturing and rearing the host cicadas, sarcophagid acoustic parasitoids continue to be a largely inaccessible system, with most data collected using indirect methods. So far, studies of males, mating behavior, effects of parasitism on host reproductive behavior and risk of parasitism have been impossible. Given that the cicadas in our study area are very difficult to observe in the field, we also used an indirect method to assess host choice and sensitivity in a member

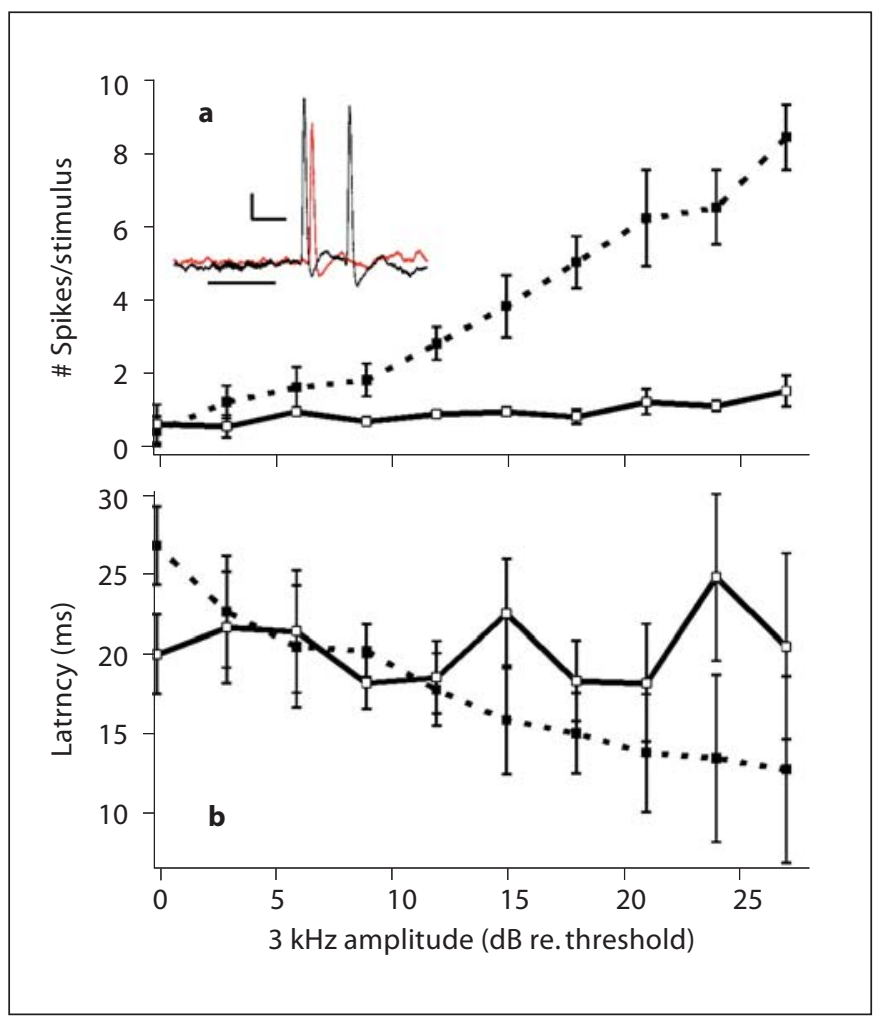

Fig. 6. Input/output curves for $3 \mathrm{kHz}$ stimuli. Mean ( \pm SD) number of spikes (a) and latency (b) to first spike. Open and closed symbols are data from interneurons $(\mathrm{n}=5)$ and afferents $(\mathrm{n}=1)$, respectively. Inset: example of interneuron response to varying stimulus amplitude. Stimulus is a $20 \mathrm{~ms}$ pulse of $3 \mathrm{kHz}$ at $71 \mathrm{~dB}$ SPL (red or light gray, respectively) and $95 \mathrm{~dB}$ SPL (black). Horizontal bar represents stimulus time. Scale: $10 \mathrm{mV}, 10 \mathrm{~ms}$.

of this group. Our data are compared to those of the only other homologous, fly-cicada system in which auditory behavior has been studied, Emblemasoma auditrix Okanagana rimosa.

\section{Fly Phonotaxis}

At our study site, at least three species of cicadas are potential hosts for Emblemasoma sp.: N. hieroglyphica, T. pruinosa and T. chloromera. Assuming the model songs are accurate, $T$. pruinosa appears to be at least one host for Emblemasoma larvae: phonotactic host choice was biased to the T. pruinosa call and attracted only larvapositing females. Similar to the response of E. auditrix to artificial signals [Köhler and Lakes-Harlan, 2001], the success of the model $T$. pruinosa song also shows that the 'wind-up' and 'wind-down' sections of the call are not necessary for fly phonotaxis. The large response to the 
T. pruinosa call notwithstanding, these data are not conclusive regarding host specificity. Indeed, the data suggest that T. chloromera is also a potential host, as the model call attracted $\sim 10 \%$ of the flies in paired broadcasts with $T$. pruinosa. In addition, flies were attracted throughout the day, overlapping the chorus time of T. chloromera and preceding the start of T. pruinosa chorus (see below). The data regarding song preference could also result from inaccuracies in the model calls themselves. Thus, to conclusively answer the question of acoustic host specificity, measurement of the responses to playbacks of numerous calls of different males would be required [Kroodsma et al., 2001].

The spectra of the T. chloromera and T. pruinosa songs exhibit large overlap. Thus, in addition to providing insight into host choice, the relatively small response to the broadcast of the T. chloromera model song also shows that frequency band per se is not sufficient to elicit comparable levels of fly phonotaxis. The temporal and frequency modulation within the T. pruinosa song thus appears to have an effect.

\section{Effects of Relative Song Intensity and Separation on}

Fly Attraction

Given the high potential of temporal overlap for T. pruinosa calls during the short duration chorus, it is predicted that decision rules for host choice that employ simultaneous comparisons of call parameters, such as intensity, are important. Numerous studies have shown that relative song intensity affects the phonotactic response of attracted insects [Forrest and Raspet, 1994; Wyttenbach and Farris, 2005], including parasitoid flies [Cade, 1979; Walker and Wineriter, 1991; Walker, 1993; Wagner, 1996]. There are four phonotactic decision rules that are based on song intensity which could explain such results: active choice based on relative intensity at the receiver (loudness); active choice based on absolute intensity at the source; choose the closest male; and respond randomly (i.e., go to any song above threshold; sometimes called passive attraction). A model of the responses generated by these decision rules shows that they can be distinguished by varying source separation and relative song power output [Forrest and Raspet, 1994]. Although varying the power output of the broadcasts is simple, varying source separation must be normalized to the phonotactic threshold of the receivers so that the amount of overlap in active space changes with separation. We used the most sensitive physiological threshold (69.2 dB SPL at $3 \mathrm{kHz}$ ) to set the separation of the two traps so that for the $10 \mathrm{~m}$ separation, the $109 \mathrm{~dB}$ SPL song had attenuated

Auditory Sensitivity in Sarcophagid Flies to threshold at the second speaker producing a normalized separation of 1.0 [normalized $5 \mathrm{~m}$ separation $=0.5$; Forrest and Raspet, 1994]. For the 1.0 separation (and greater), the predicted response proportions are identical for all decision rules [Forrest and Raspet, 1994]. Thus, the response proportion at $10 \mathrm{~m}$ separation, $\Delta 6 \mathrm{~dB}$ is important because it serves as a control for use of the threshold to set the normalized separation to 1.0. The response proportion for this condition ( 0.241 to quieter source; table 2 ) is nearly identical to that predicted by the model ( 0.25 to quieter source; $\left.\chi^{2}=0.011, p=0.915\right)$, suggesting that, as in E. auditrix [Köhler and Lakes-Harlan, 2001], $\sim 69 \mathrm{~dB}$ SPL is indeed the response threshold in the field.

Unlike the situation in larger relative separations $(\geq 1.0)$, the predicted response proportions for the decision rules differ as the call sources are moved closer together [Forrest and Raspet, 1994]. For these conditions we have only two data sets, limiting our conclusions. Although both response proportions at the 0.5 relative separation are in good agreement with those predicted for phonotaxis based on loudness $(\Delta 3 \mathrm{~dB}, 0.212 \mathrm{vs}$. predicted $0.17, \mathrm{p}=0.5 ; \Delta 6 \mathrm{~dB}, 0.242$ vs. predicted $0.28, \mathrm{p}=0.6)$ and appear to differ with those predicted for passive attraction $(\Delta 3 \mathrm{~dB}, 0.212 \mathrm{vs}$. predicted $0.5, \mathrm{p}=0.003 ; \Delta 6 \mathrm{~dB} 0.242$ vs. predicted $0.353, \mathrm{p}=0.089)$, more data are required to resolve which decision rule is employed.

\section{Fly Auditory Physiology}

A potential mechanism for improving signal detection is an increase in the signal-to-noise ratio through spectral filtering, in which best sensitivity is matched to the dominant frequencies of the signal [Green and Swets, 1974; Capranica, 1978]. This null hypothesis is predictive, as a matched filter is commonly exhibited across vertebrates and insects [Schildberger, 1984; Gerhardt and Schwartz, 2001; Gentner and Margoliash, 2003]. Our results are consistent with this hypothesis, showing that the frequency sensitivity of interneurons in flies attracted to the T. pruinosa song is well matched to that of the call (fig. 5). As with E. auditrix [Lakes-Harlan et al., 1999], tuning in Emblemasoma sp. is not due to mechanical tuning of the tympanal membrane. Robert et al. [1999] used a subset of the flies from our study to measure the mechanical response in the tympanal organs, revealing a broadband resonance from 1 to $30 \mathrm{kHz}$. Thus, the tuned physiological response shown here suggests that there is either intrinsic (e.g., physiological) tuning or subsequent mechanical mechanisms that filter stimuli around the T. pruinosa spectrum [see Lakes-Harlan et al., 1999]. 
Considering our results, the mismatch in tuning found in E. auditrix is not a characteristic of this taxon and, at least with respect to the $O$. rimosa song, phonotactic decisions by $E$. auditrix are made with less than optimal frequency information [Hennig et al., 2004]; such an interpretation is consistent with the broad tuning of the E. auditrix behavioral response [Köhler and Lakes-Harlan, 2001].

Although behavioral thresholds between Emblemasoma sp. and E. auditrix are similar (see above), comparisons between physiological thresholds are difficult, as those previous studies used different stimulus and threshold protocols [Lakes-Harlan et al., 1999, 2000; but see Stumpner and Lakes-Harlan, 1996]. E. auditrix is reported to be $\sim 18 \mathrm{~dB}$ more sensitive at the best frequency. However, in contrast to the methods used here, E. auditrix thresholds were calculated based on averaged responses to 20 repetitions and a longer duration stimulus (50 ms, producing $4 \mathrm{~dB}$ more energy/stimulus pulse).

\section{Diel Singing Patterns and Parasitoids}

Several abiotic and/or biotic factors vary with the diel behavior patterns of singing insects [Walker, 1983; Loher, 1989; Forrest, 1998; Römer, 1998]. In our study we found that chorus times in T. chloromera (pre-noon) and T. pruinosa (dusk) were correlated with certain environmental conditions (table 1). As shown for other members of the genus Tibicen [Hastings and Toolson, 1991], such correlations might reflect differences in the ability to thermoregulate, with cicadas that are endothermic singing at different times than those that are ectothermic, such as T. chloromera [Sanborn et al., 1995, 2003; Sanborn, 2000]. Whether singing in T. pruinosa and T. chloromera is physiologically restricted by environmental conditions or not, correlations between chorus timing and environmental conditions might also reflect the use of these conditions as cues for timing behavior appropriately [Alexander, 1960; Loher, 1972; Crawford and Dadone, 1979; Loher and Orsak, 1985].

Diel variation in noise levels and signal transmission through the environment could also constrain singing times [Forrest, 1994; Römer, 1998]; increasing the reception of an acoustic signal by potential mates is probably facilitated by signaling at times when there is less background noise [Walker, 1983; Greenfield, 1988; Doolan and Young, 1989; Sueur, 2002] or when signal propagation is maximum [Henwood and Fabrick, 1979; Young, 1981]. Indeed, noise in the form of concurrent signaling by heterospecifics creates acoustic interference [Latimer and Broughton, 1984; Bailey and Morris, 1986], causing choruses to shift to quieter times [Greenfield, 1988]. Although the temporal properties of the T. pruinosa and T. chloromera songs are quite different, their spectral ranges are similar (overlapping from ca. 2.5 to $6.0 \mathrm{kHz}$; fig. 1), potentially causing congeneric acoustic interference. Hypothetically, such a cost would favor the diel displacement in singing times observed in this study.

In addition to physiological and acoustical constraints, our data add a factor correlated to differences in diel chorus times: risk of attracting parasitoid flies. For the hosts of acoustic parasitoids, costs include reductions in reproductive behavior and increased mortality [Cade, 1984; Adamo et al., 1995; Allen, 1995]. Consequently, selection from acoustic parasitoids has affected male singing behavior in a variety of taxa [Kolluru, 1999; see Zuk and Kolluru, 1998 for review]. One potential counter-adaptation is a shift in the diel patterns of male singing behavior to times with reduced risk [Walker, 1983; Zuk et al., 1993; Allen, 1998; Bertram et al., 2004]. A second potential defense against acoustic parasitoids (and predators) is a reduction in the distribution of singing times, in which increased temporal aggregation (i.e., greater diel synchrony) might reduce the risk of parasitism through an encounter-dilution effect [Alexander, 1975; Walker, 1983; Mooring and Hart, 1992]. Several species of cicada are known to exhibit tightly timed, short duration choruses [e.g., 10-25 min; Alexander, 1960; Crawford and Dadone, 1979; Gogala and Riede, 1995]. Previously, however, there were few data describing any biotic correlates to these diel signaling patterns in cicadas, such as the attraction of acoustic parasitoids.

Our observations of fly attraction and the diel chorus patterns of $T$. pruinosa and T. chloromera suggest that selective pressure from Emblemasoma sp. might contribute to the daily timing of sexual signaling in male cicadas. Although our field study cannot resolve a causeeffect relationship between diel chorus timing and parasitoid attraction, the short duration chorus in T. pruinosa should at least function to avoid longer exposure to parasitoids that are clearly phonotactic throughout the day. Also, the significantly shorter duration of the $T$. pruinosa chorus relative to that of $T$. chloromera could represent the temporal analog of a selfish herd and reduce individual risk by increasing chorus size [Ryan et al., 1981]. 


\section{Acknowledgements}

E. Nelson provided invaluable help with the cicada census. M. Holland, M. Baker and the staff of the University of Mississippi Biological Field Station generously provided space for the sound trapping experiments. H.E. Bass provided playback equipment. The authors would like to thank T.E. Moore for identifying the cicadas from initial recordings of their songs. R. Cocroft, A. Mason, P. Buston, P. Sherman, G.L. Miller and R. Holberton offered many helpful comments on the project or manuscript. Funding for this work came from USDA-ARS cooperative agreement grant 58-6408-2-104 to the National Center of Physical Acoustics and NIH Grant \# R01 DC00103 to RRH.

\section{References}

-Adamo SA, Robert D, Hoy RR (1995) Effects of a tachinid parasitoid, Ormia ochracea, on the behaviour and reproduction of its male and female field cricket hosts (Gryllus spp.). J Insect Physiol 41:269-277.

Aldrich JM (1916) Sarcophaga and Allies in North America. Entomological Society of America, Thomas Say Foundation, Vol 1, La Fayette, Indiana.

Alexander RD (1960) Sound communication in Orthoptera and Cicadidae. In: Animal Sounds and Communication (Lanyon WE, Tavolga WN, eds), pp 38-92. AIBS Publication No. 7. Washington, D.C.

Alexander RD (1975) Natural selection and specialized chorusing behavior in acoustical insects. In: Insects, Science and Society (Pimental D, ed), pp 35-77. New York: Academic Press.

-Allen GR (1995) The biology of the phonotactic parasitoid, Homotrixa sp. (Diptera: Tachinidae), and its impact on the survival of male Sciarasaga quadrata (Orthoptera: Tettigoniidae) in the field. Ecol Entomol 20:103-110.

-Allen GR (1998) Diel calling activity and field survival of the bushcricket, Sciarasaga quadrata (Orthoptera: Tettigoniidae): a role for sound locating parasitic flies? Ethology 104:645-660.

-Bailey WJ, Morris GK (1986) Confusion of phonotaxis by masking sounds in the bushcricket Conocephalus brevipennis (Tettigoniidae: Conocephalinae). Ethology 73:19-28.

-Bertram SM, Orozco SX, Bellani R (2004) Temporal shifts in conspicuousness: Mate attraction displays of the Texas field cricket, Gryllus texensis. Ethology 110:963-975.

-Burk T (1982) Evolutionary significance of predation on sexually signaling males. Fla Entomol 65:90-104.

Cade WH (1975) Acoustically orienting parasitoids: fly phonotaxis to cricket song. Science 190:1312-1313.

Cade WH (1979) The evolution of alternative reproductive strategies in field crickets. In: Sexual Selection and Reproductive Competition in Insects (Blum MS, Blum NA, eds), pp 343-380. New York: Academic Press.

Cade WH (1984) Effects of fly parasitoids on nightly calling duration in field crickets. Can J Zool 62:226-228.

-Capranica RR (1978) Auditory processing in anurans. FASEB J 37:2324-2328.
Chatfield C (1989) The Analysis of Time Series. New York: Chapman and Hall.

Crawford CS, Dadone MM (1979) Onset of evening chorus in Tibicen marginalis (Homoptera: Cicadidae) Environ Entomol 8:11571160.

Doolan JM, Young D (1989) Relative importance of song parameters during flight phonotaxis and courtship in the bladder cicada Cystosoma saundersii. J Exp Biol 141:113-131.

Edgecomb RS, Robert D, Read MP, Hoy RR (1995) The tympanal hearing organ of a fly: phylogenetic analysis of its morphological origins. Cell Tissue Res 282:251-268.

Forrest TG (1994) From sender to receiver: propagation and environmental effects on acoustic signals. Am Zool 34:644-654.

Forrest TG (1998) Temporal rhythms in the signals of insects. Proc. 16th International Con gress on Acoustics and 135th meeting Acous tical Society of America 1803-1804

Forrest TG, Raspet R (1994) Models of female choice in acoustic communication. Behav Ecol 5:293-303.

Fowler HG (1987) Field behavior of Euphasiop teryx depleta (Diptera: Tachinidae): phono tactically orienting parasitoids of mole crickets (Orthoptera: Gryllotalpidae: Scapteris cus). J NY Entomol Soc 95:474-480.

Gentner T, Margoliash D (2003) The neuroethology of vocal communication: perception and cognition. In: Acoustic Communication (Simmons AM, Popper AN, Fay RR, eds), pp 324-386. New York: Springer-Verlag.

Gerhardt HC, Schwartz JJ (2001) Auditory tuning and frequency preferences in anurans. In: Anuran Communication (Ryan MJ, ed), pp 73-85. Washington D.C.: Smithsonian.

Gogala M, Riede K (1995) Time sharing of song activity by cicadas in Temengor Forest Reserve, Hulu Perak, and in Sabah, Malaysia. Malay Nat J 48:297-305.

Green DM, Swets JA (1974) Signal Detection Theory and Psychophysics. New York: Kreiger.

Greenfield MD (1988) Interspecific acoustic interactions among katydids Neoconocephalus: inhibition-induced shifts in diel periodicity. Anim Behav 36:684-695.
Hastings JM, Toolson EC (1991) Thermoregulation and activity patterns of two syntopic cicadas Tibicen chiricahua and T. duryi (Homoptera: Cicadidae), in central New Mexico. Oecologia 85:513-520.

Hennig RM, Franz A, Stumpner A (2004) Processing of auditory information in insects. Microsc Res Tech 63:351-374.

Henwood K, Fabrick A (1979) A quantitative analysis of the dawn chorus: temporal selection for communicatory optimization. Am Nat 114:260-274

Hosmer DW, Lemeshow S (1989) Applied Logistic Regression. New York: Wiley and Sons.

Josephson RK, Young D (1979) Body temperature and singing in the bladder cicada, Cystosoma saundersii. J Exp Biol 80:69-81.

Köhler U, Lakes-Harlan R (2001) Auditory behaviour of a parasitoid fly (Emblemasoma auditrix, Sarcophagidae, Diptera). J Comp Physiol A 187:581-587.

Kolluru GR (1999) Variation and repeatability of calling behavior in crickets subject to a phonotactic parasitoid fly. J Insect Behav 12: 611-626.

Kroodsma DE, Byers BE, Goodale E, Johnson S, Liu W-C (2001) Pseudoreplication in playback experiments, revisited a decade later. Anim Behav 61:1029-1033.

Lakes-Harlan R, Heller K-G (1992) Ultrasoundsensitive ears in a parasitoid fly. Naturwissenschaften 79:224-226.

Lakes-Harlan R, Stolting H, Stumpner A (1999) Convergent evolution of insect hearing organs from a preadaptive structure. Proc $\mathrm{R}$ Soc Lond B 266:1161-1167.

Lakes-Harlan R, Stolting H, Moore TE (2000) Phonotactic behaviour of a parasitoid fly (Emblemasoma auditrix, Diptera, Sarcophagidae) in response to the calling song of its host cicada (Okanagana rimosa, Homoptera, Cicadidae). Zoology 103:31-39.

Latimer W, Broughton WB (1984) Acoustic interference in bush crickets; a factor in the evolution of singing insects? J Nat Hist 18: 599-616.

Lehmann GUC (2003) Review of biogeography, host range and evolution of acoustic hunting in Ormiini (Insecta, Diptera, Tachinidae), parasitoids of night-calling bushcrickets and crickets (Insecta, Orthoptera Ensifera). Zool Anz 242:107-120. 
-Lehmann GUC, Heller K-G (1998) Bushcricket song structure and predation by the acoustically orienting parasitoid fly Therobia leonidei (Diptera: Tachinidae: Ormiini). Behav Ecol Sociobiol 43:239-245.

Loher W (1972) Circadian control of stridulation in the cricket Teleogryllus commodus Walker. J Comp Physiol 79:173-190.

Loher W (1989) Temporal organization of reproductive behavior. In: Cricket Behavior and Neurobiology (Huber F, Moore TE, Loher W, eds), pp 83-113. Ithaca, NY: Cornell University Press.

- Loher W, Orsack LJ (1985) Circadian patterns of premating behavior in Teleogryllus oceanicus Le Guillou under laboratory and field conditions. Behav Ecol Sociobiol 16:223231.

Lopes HS (1971) Notes on Emblemasoma and Pessoamyia (Diptera, Sarcophagidae). Rev Brasil Biol 31:89-97.

Lopes HS (1981) Notes on American Sarcophagidae (Diptera). Rev Brasil Biol 41:149-152.

Mooring MS, Hart BL (1992) Animal grouping for protection from parasites: selfish herd and encounter-dilution effects. Behaviour 123:173-193.

-Oshinsky ML, Hoy RR (2002) Physiology of the auditory afferents in an acoustic parasitoid fly. J Neurosci 22:7254-7263.

Pape T (1990) Revisionary notes on American Sarcophaginae (Diptera Sarcophagidae). Tijdschrift Entomol 133:43-74.

Robert D, Amoroso J, Hoy RR (1992) The evolutionary convergence of hearing in a parasitoid fly and its cricket host. Science 258:11351137.

- Robert D, Miles RN, Hoy RR (1999) Tympanal hearing in the sarcophagid parasitoid fly Emblemasoma sp.: The biomechanics of directional hearing. J Exp Biol 202:1865-1876.

Römer H (1998) The sensory ecology of acoustic communication in insects. In: Comparative Hearing: Insects (Hoy RR, Popper AN, Fay RR, eds), pp 63-96. New York: Springer-Verlag.
Ryan MJ, Tuttle MD, Taft LK (1981) The cost and benefits of frog chorusing behavior. Behav Ecol Sociobiol 8:273-278.

Sanborn AF (2000) Comparative thermoregulation of sympatric endothermic and ectothermic cicadas (Homoptera: Cicadidae: Tibicen winnemanna and Tibicen chloromerus). J Comp Physiol A 186:551-556.

-Sanborn AF, Heath JE, Heath MS, Noriega FG (1995) Thermoregulation by endogenous heat production in two South American grass dwelling cicadas (Homoptera: Cicadidae: Proarna). Fla Entomol 78:319-328.

Sanborn AF, Villet MH, Phillips PK (2003) Hotblooded singers: endothermy facilitates crepuscular signaling in African platypleurine cicadas (Hemiptera: Cicadidae: Platypleura spp.). Naturwissenschaften 90:305-308.

-Schildberger K (1984) Temporal selectivity of identified auditory neurons in the cricket brain. J Comp Physiol 155:171-185.

Schniederkotter K, Lakes-Harlan R (2004) Infection behavior of a parasitoid fly, Emblemasoma auditrix, and its host cicada Okanagana rimosa. J Insect Sci 4:Article 36.

Shapiro L (1995) Parasitism of Orchelimum katydids (Orthoptera: Tettigoniidae) by Ormia lineifrons (Diptera: Tachinidae). Fla Entomol 78:615-616.

Soper RS, Shewell GE, Tyrrell D (1976) Colcondamyia auditrix nov. sp. (Diptera: Sarcophagidae), a parasite which is attracted by the mating song of its host, Okanagana rimosa (Homoptera: Cicadidae). Can Entomol 108:61-68.

Stumpner A, Lakes-Harlan R (1996) Auditory interneurons in a hearing fly (Therobia leonidei, Ormiini, Tachinidae, Diptera). J Comp Physiol A 178:227-233.

-Stumpner A, Allen GR, Lakes-Harlan R (2007) Hearing and frequency dependence of auditory interneurons in the parasitoid fly $\mathrm{Ho}$ motrixa alleni (Tachinidae: Ormiini). J Comp Physiol A 193:113-125.
Sueur J (2002) Cicada acoustic communication: potential sound partitioning in a multispecies community from Mexico (Hemiptera: Cicadomorpha: Cicadidae). Biol J Linn Soc Lond 75:379-394.

Wagner WE (1996) Convergent song preferences between female field crickets and acoustically orienting parasitoid flies. Behav Ecol 7: 279-285.

Walker TJ (1983) Diel patterns of calling in nocturnal Orthoptera. In: Orthopteran Mating Systems: Sexual Competition in a Diverse Group of Insects (Gwynne DT, Morris GK, eds), pp 45-71. Boulder, CO: Westview Press.

Walker TJ (1989) A live trap for monitoring Euphasiopterx and tests with E. ochracea (Diptera: Tachinidae). Fla Entomol 72:314-319.

Walker TJ (1993) Phonotaxis in female Ormia ochracea (Diptera: Tachinidae), a parasitoid of field crickets. J Insect Behav 6:389-410.

Walker TJ, Wineriter SA (1991) Hosts of a phonotactic parasitoid and levels of parasitism (Diptera: Tachinidae: Ormia ochracea). Fla Entomol 74:554-559.

Wineriter SA, Walker TJ (1990) Rearing phonotactic parasitoid flies (Diptera: Tachinidae, Ormiini, Ormia spp). Entomophaga 35:621632.

Wyttenbach RW, Farris HE (2005) Psychophysics in insect hearing. Microsc Res Tech 63: 375-387.

Young AM (1981) Temporal selection for communicatory optimization: the dawn-dusk chorus as an adaptation in tropical cicadas. Am Nat 117:826-829.

Zar JH (1984) Biostatistical Analysis. Englewood Cliffs, NJ: Prentice-Hall.

Zuk M, Kolluru GR (1998) Exploitation of sexual signals by predators and parasitoids. Q Rev Biol 73:415-438.

Zuk M, Simmons LW, Cupp L (1993) Calling characteristics of parasitized and unparasitized populations of the field cricket Teleogryllus oceanicus. Behav Ecol Sociobiol 33: 339-343. 